\title{
Guest editorial: IJAMT special issue on: product-service systems
}

\author{
Essam Shehab • Rajkumar Roy
}

Published online: 13 November 2010

(C) Springer-Verlag London Limited 2010

Manufacturing industries are shifting their offerings from selling a physical product to sell functions through product-service system (PSS) business model. This enables manufacturing companies to generate more revenue and better satisfying and exceeding customer expectations. The PSS has great impacts on the product life cycle, the customer and the relationship between the product, business processes, organisational structure and cost. Therefore, there is increasing need to understand these challenges and issues that are critical to the success of developing PSS. Scenarios of PSS in different industrial domains are required to illustrate the implementation success factors of such model. Several manufacturing organisations have passed through this transformation and have good insight and knowledge about the challenge. There is a need to enhance multidisciplinary research in the PSS area.

This Special Issue of the International Journal of Advanced Manufacturing Technology presents ten selected papers that cover state of the art research in a number of PSS areas. Some of these papers have been selected from the proceedings of the 6th International Conference on Manufacturing Research (ICMR 2008) held at Brunel University, UK on 9-11 September 2008. This special issue commences with two papers on PSS for machine tool industry. Greenough and Grubic's paper focuses on modelling condition-based maintenance to deliver a service

\footnotetext{
E. Shehab $(\bowtie) \cdot$ R. Roy

Decision Engineering Centre, Manufacturing Department, Cranfield University,

Building 50, Cranfield,

Bedfordshire MK43 0AL, UK

e-mail: e.shehab@cranfield.ac.uk

R. Roy

e-mail: r.roy@cranfield.ac.uk
}

to machine tool users. The paper describes the development and validation of two software tools to explore the relationship between prognostics and health management technologies and servitization in the machine tool industry. The second paper presents the concept of an industrial product-service system for CNC machine tool (mt-iPSS) based on the provision and enhancement of machining capabilities by Zhu et al. An architecture is proposed to enable the mt-iPSS from the aspects of both hardware and software. Huang et al. investigate how the new concept of PSS can be used and extended to transform, elevate and revitalise traditional equipment manufacturing industry such as the mould and die sector. PSS encompasses several challenges in terms of innovation, organisation structure, information flow and uncertainties. Lee and Abu Ali in their paper present an operating system for innovation by offering a methodology for systematic innovative thinking and a toolbox of interconnected tools that can aid in the transformation of core product competencies into effective product-service amalgamations. An approach for a modular organisation structure with the extension of modular organisation units is described by Meier et al. The structure is supporting the flexible use of resources of networking companies. Planning the resources for the integrated PSS delivery is a complex problem that also needs new planning methods. The metaheuristic optimisation strategy is an approach to establish a real-time planning and control. Durugbo et al. present a review of diagrammatic information flow tools which are designed to describe a system through its functions. A case study of selection lasermelting technology implemented as PSS has been employed to show the application of information flow modelling for PSS design. Mittermeye et al. argue that although PSS possess great potential, the health care sector has not given an attention of the research community. They 
briefly review the challenges and benefits of implementing PSS and analyses the special characteristics of the health care market. The global transition towards service orientation is posing challenges in cost estimation for manufacturers driven by the uncertainties. Erkoyuncu et al. combine literature in service and uncertainty in cost estimation to propose the components of a service delivery system, classification of sources of uncertainty based on supply and demand and the suitable uncertainty-modelling methods for service cost estimation. Kuo develops a renting system in a reverse logistics environment on the basis of the PSS theory. The system includes the complete management of product examination, maintenance, upgrading, products recycling and final waste disposal. The simulation model is analysed by using three different scheduling and dispatching rules. De Coster examines the forecasting implications for PSS applications in the telecoms sector. The paper develops a revenue model which identifies three generic revenue. In summary, the ten papers have presented an overview of the current challenges in the PSS research and a few directions for the future.

We would like to express our thanks to both the authors and reviewers for their time and effort in producing and ensuring the quality of the included papers. We are also grateful to Professor John Davies (Editor-in-Chief IJAMT), Professor Kai Cheng (Associate Editor for Europe) and the members of the Editorial Board of the Journal for encouraging us to prepare this issue, for the staff at Springer Publishing, in particular Ms. Claudia Kehl for their help in finalising this special issue. 